\title{
Which bronchodilator reversibility criteria can predict severe acute exacerbation in chronic obstructive pulmonary disease patients?
}

Junghyun Kim, Woo Jin Kim², Chang-Hoon Lee ${ }^{3 *}$, Sang Haak Lee", Myung-Goo Lee ${ }^{5}$, Kyeong-Cheol Shin ${ }^{6}$, Kwang Ha Yoo ${ }^{7}$, Ji-Hyun Lee ${ }^{8}$, Seong Yong Lim', Ju Ock Na ${ }^{10}$, Hun-Gyu Hwang ${ }^{11}$, Yoonki Hong ${ }^{2}$, Myoung Nam Lim², Chul-Gyu Yoo ${ }^{3}$, Ki Suck Jung ${ }^{12}$ and Sang-Do Lee ${ }^{13}$

\begin{abstract}
Background: It is unclear whether various bronchodilator reversibility (BDR) criteria affect the prognosis of chronic obstructive pulmonary disease (COPD). The aim of this study is to evaluate the impact of positive BDR defined according to various BDR criteria on the risk of severe acute exacerbation (AE) in COPD patients.

Methods: Patients from four prospective COPD cohorts in South Korea who underwent follow-up for at least 1 year were enrolled in this study. The assessed BDR criteria included the Global Initiative for Chronic Obstructive Lung Disease (GOLD), American Thoracic Society (ATS), American College of Chest Physicians, (ACCP), major criteria of the Spanish definition of asthma-COPD overlap syndrome (ACOS), criteria compatible with ACOS in the Global Initiative for Asthma (GINA), and European Respiratory Society (ERS). The rate of patients with severe AE who required hospitalization within 1 year due to BDR results according to each set of criteria was analyzed using logistic regression models.
\end{abstract}

Results: Among a total of 854 patients, the BDR-positive cases varied according to the criteria used. There was a 3.5\% positive BDR rate according to GINA and a $29.9 \%$ rate according to the ATS criteria. Positive BDR according to the GOLD criteria was significantly associated with a decreased risk of severe AE (adjusted odds ratio $(a O R)=0.38 ; 95 \%$ Confidence interval $(\mathrm{Cl})=0.15-0.93)$. This result remained statistically significant even in a sensitivity analysis that included only participants with a smoking history of at least 10 pack-years and in the analysis for the propensity score-matched participants.

Conclusions: Among different criteria for positive BDR, the use of the GOLD ones was significantly associated with a decreased risk of severe AE in COPD patients. Increase use of ICS/LABA may have affected this relationship.

Keywords: Bronchodilator reversibility, COPD, Severe acute exacerbation

\footnotetext{
* Correspondence: kauri670@empal.com

${ }^{3}$ Division of Pulmonary and Critical Care Medicine, Department of Internal

Medicine, Seoul National University Hospital, 101 Daehak-Ro, Jongno-Gu,

Seoul 03080, Republic of Korea

Full list of author information is available at the end of the article
} 


\section{Background}

Chronic obstructive lung disease (COPD) is a well-known disease associated with a negative clinical outcome, including lung function decline and acute exacerbation (AE) [1]. The incidence and mortality of COPD have seen a global increase, and greater comprehension of the characteristics and management of this disease is needed [2-4].

The key pathophysiology of COPD is persistent and progressive airflow limitation [1]. However, airflow obstruction is reversible to some extent following the administration of a short-acting bronchodilator in many COPD patients. The prevalence of the positive bronchodilator reversibility (BDR) in COPD patients varies and has been reported as $15-50 \%[5,6]$. Studies have suggested that a positive BDR could be a phenotypic characteristic [7]. However, it remains unclear whether a positive response in the BDR test has an impact on the treatment outcome of COPD patients. One study reported that the response of patients response to pharmacological treatments cannot be prejudged by the acute response (reversibility) to shortacting bronchodilators [8]. A lack of an acute response to bronchodilators was not associated with a long-term response to maintenance bronchodilator treatment [9]. Several studies showed that COPD patients with a positive BDR were associated with a worse outcome such as increased risk of $\mathrm{AE}$ and re-hospitalization [10,11]. On the other hand, other studies reported an association between BDR positivity and an improvement in the clinical course in COPD patients [12].

There is no established standard definition of relevant BDR [8], although different criteria for BDR positivity which have been used in a clinical context and in research, including the Global Initiative for Chronic Obstructive Lung Disease (GOLD) [1], American Thoracic Society (ATS) [13], American College of Chest Physicians (ACCP) [14], major criteria of the Spanish definition of asthmaCOPD overlap syndrome [15], criteria compatible with ACOS in the Global Initiative for Asthma (GINA) [16], and European Respiratory Society (ERS) [17]. To the best of our knowledge, no study has yet compared the outcomes according to these BDR criteria.

The aim of this study was thus investigate the impact of positive BDR on the risk of severe AE according to different BDR criteria in COPD patients.

\section{Methods}

We enrolled participants from four different prospective COPD cohort studies in South Korea: Seoul National University Hospital (SNUH) Airway Registry (NCT02527486), COPD in Dusty Area (CODA) Registry (KCT0000552), Korean COPD Subgroup Study (KOCOSS) (NCT02800499), and Korean Obstructive Lung Disease Cohort (KOLD). All COPD studies were registered with the exception of KOLD, which had been launched 12 years previously. The study design and methods were approved by the Institutional Review Board (IRB) of Seoul National University Hospital (IRB No. H-1507-030-686).

Participants who were over 40 years of age and who showed a post-bronchodilator forced expiratory volume in $1 \mathrm{~s}(\mathrm{FEV} 1) /$ forced vital capacity $(\mathrm{FVC})<0.7$ were included. Those who were diagnosed with asthma, those not followed-up for at least 1 year, or those with a lack of information were excluded. Duplicate patients who were included in two or more cohorts were also excluded.

Various criteria for BDR positivity have been used both clinically and in research. Available definitions are distinguishable by the representative level of lung function (FEV1 [1, 14-17] or FVC [13], and whether to adopt an absolute or percentage change in that level. Several definitions use both absolute and percentage changes $[1,13,15,16]$ in pulmonary function to compensate for discordance in improvement from the baseline after bronchodilator application caused by the severity of COPD and thus provide a more comprehensive approach. The GOLD criteria for BDR positivity is an increase of $12 \%$ and $200 \mathrm{ml}$ in post-bronchodilator FEV1 [1], the ATS criteria for BDR positivity is an increase of $12 \%$ and $200 \mathrm{ml}$ in FEV1 or FVC [13], the ACCP requires an increase of $15 \%$ in FEV1 [14]. The major criteria of the Spanish definition of ACOS are an increase of $15 \%$ and $400 \mathrm{ml}$ in FEV1 [15]. The criteria compatible with ACOS in GINA require an increase of $12 \%$ and $400 \mathrm{ml}$ in FEV1 [16], while the ERS criteria are that post FEV1\%- pre FEV1\% $\geq 10 \%$ [17]. Finally, a criterion that was introduced by a study free of biases from sample size and sex was an 8\% increase in FEV1 [12].

Baseline information of the study population, including demographic characteristics, smoking habits, and comorbidities was investigated in each cohort. Symptom scores from the COPD assessment test (CAT), St. George's respiratory questionnaire (SGRQ), and the modified Medical Research Council (mMRC) dyspneascale were collected, as well as any severe AE event within 1 year prior to enrollment. Spirometry tests were performed using standardized equipment by qualified technicians following the ATS/ERS guidelines. Spirometry tests were repeated at least three times to achieve within- and between-maneuver acceptability criteria. After the initial spirometry testing (pre-dose spirometry), a dose of $100 \mu \mathrm{g}$ of salbutamol was fully inhaled in one breath, and the breath was then held for 5 to $10 \mathrm{~s}$ before exhalation. Two separate doses (total dose $200 \mu \mathrm{g}$ ) were administered at approximately 30-s intervals. Three additional spirometry tests were performed between 10 and 15 min later for reversibility testing [18]. The medication possession ratios (MPRs) of the treatment drugs, including inhaled corticosteroid combined with long-acting 
beta agonists (ICS/LABA) and long-acting muscarinic antagonist (LAMA), were calculated as the total days of prescription days of each drug category divided by the total days of follow-up. All measurements for lung function were collected prospectively.

This study investigated the incidence of severe $\mathrm{AE}$ within 1 year of enrollment. All participants were asked to answer a questionnaire regarding the experience of $\mathrm{AE}$ of COPD since the previous visit at every follow-up visit. The definition of severe AE was any event that required an emergency room visit or hospital admission due to acute aggravation of COPD symptoms.

We compared those who experienced at least one severe $\mathrm{AE}$ event within 1 year to those without a severe $\mathrm{AE}$ event by using either a Mann-Whitney test or a Student's $t$-test for continuous variables and a chi-squared test for categorical variables. Variables that showed a statistically significant difference between groups were included as adjustment covariates to investigate the effects of each set of BDR criteria on the incidence of severe $\mathrm{AE}$ in multivariable logistic models. Crude odds ratios (cORs), adjusted ORs (aORs), 95\% confidence intervals (CIs), and the Akaike Information Criterion (AIC) were used to evaluate the models that included each set of BDR criteria as a principal variable. We carried out a sensitivity analysis for patients with a smoking history $\geq 10$ pack-years (PY). The effects of treatment drugs (ICS/LABA and LAMA) and FEV1\% on the relationship between each of the BDR criteria and severe $\mathrm{AE}$ were also explored. A propensity score for a positive BDR was also calculated by using various covariates and an analysis was conducted in the propensity score-matched participants. A $p$-value $<0.05$ was regarded as statistically significant. SPSS 20.0 (IBM Corp., Armonk, NY, USA) and STATA 14.1 (StataCorp, TX, USA) were used for statistical analysis.

\section{Results}

Among the patients in the four cohorts, patients with more than 1-year of follow-up data were selected. As shown in the flow chart for enrollment (Fig. 1), a total of 854 patients were included in this study.

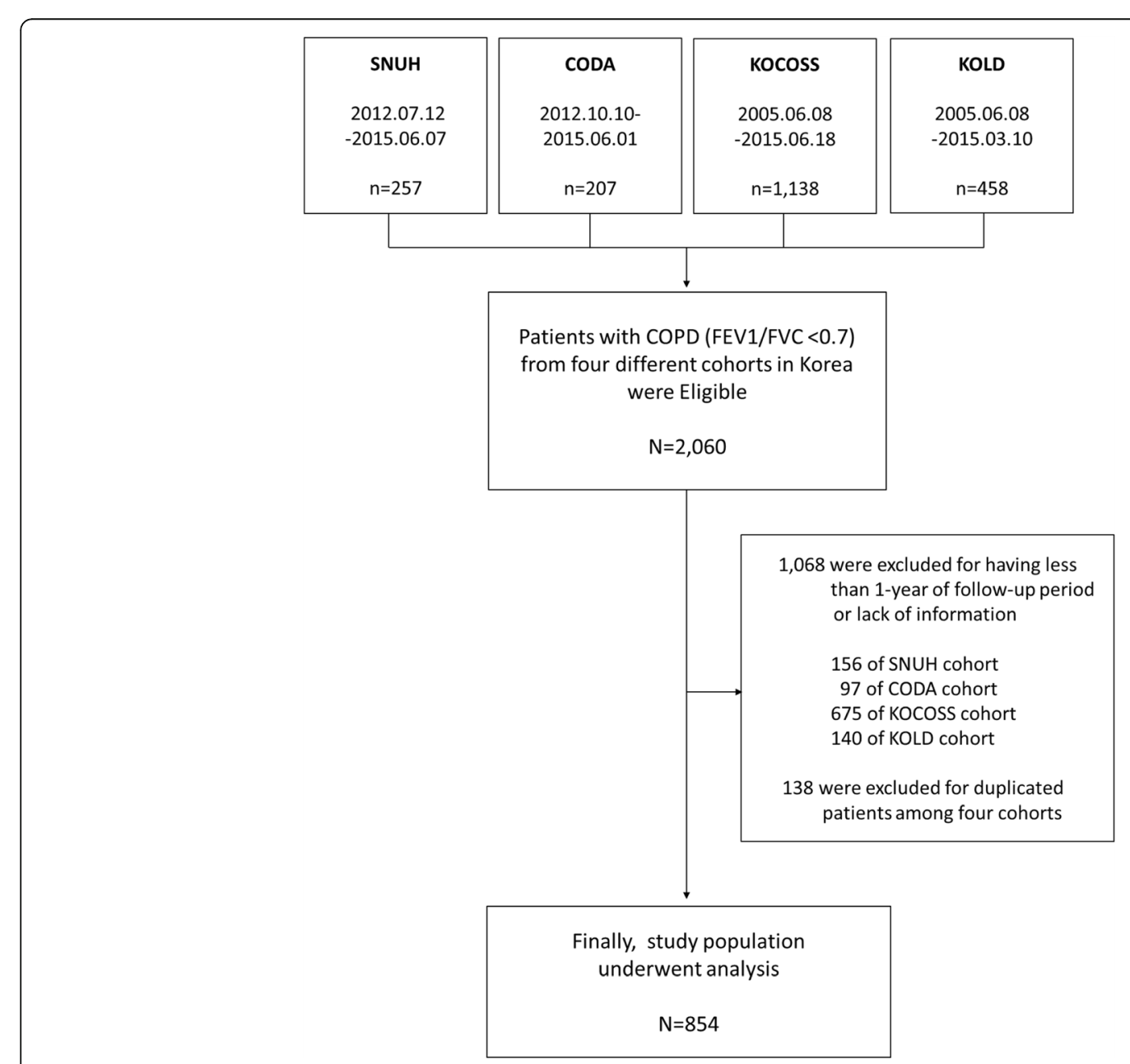

Fig. 1 Flow chart showing the enrollment process for participants. SNUH Seoul National University Hospital Cohorts, CODA COPD in Dusty Area, KOCOSS Korean COPD Subgroup Study, KOLD Korean Obstructive Lung Disease Cohort 
The baseline characteristics of the patients are shown in Table 1. The mean CAT score was 15.4 (SD 7.9), and the mean SGRQ and mMRC scores were 33.1 (SD 17.3) and 1.61 (SD 1.01), respectively. About 10.9\% of patients

Table 1 Baseline characteristics of the participants

\begin{tabular}{|c|c|}
\hline Characteristics & All participants $(n=854)$ \\
\hline Age (mean, SD) & $68.3(7.6)$ \\
\hline Male (N, \%) & $776(90.9)$ \\
\hline \multicolumn{2}{|l|}{ Cohorts registration ( $\mathrm{N}, \%)$} \\
\hline SNUH & $101(11.8)$ \\
\hline CODA & $110(12.9)$ \\
\hline KOCOSS & $325(38.1)$ \\
\hline KOLD & $318(37.2)$ \\
\hline BMI (mean, SD) & $23.0(3.4)$ \\
\hline Weight (mean, SD) & $61.7(10.7)$ \\
\hline Height (mean, SD) & $163.6(7.4)$ \\
\hline \multicolumn{2}{|l|}{ Smoking habits } \\
\hline None smoker & $81 / 851(9.5)$ \\
\hline Ex-smoker & $538 / 851(63.2)$ \\
\hline Current smoker & $232 / 851(27.3)$ \\
\hline Pack-year (mean, SD) & $43.3(28.7)$ \\
\hline \multicolumn{2}{|l|}{ Comorbidities (N, \%) } \\
\hline Diabetes mellitus & $111 / 825(13.5)$ \\
\hline Heart disease & $67 / 841(8.0)$ \\
\hline Cancer & $24 / 519(4.6)$ \\
\hline \multicolumn{2}{|l|}{ Symptom scores } \\
\hline CAT (mean, SD) & $15.4(7.9)$ \\
\hline CAT $\geq 10(\mathrm{~N}, \%)$ & $455 / 614(74.1)$ \\
\hline SGRQ (mean, SD) & $33.1(17.3)$ \\
\hline $\mathrm{SGRQ} \geq 25(\mathrm{~N}, \%)$ & $258 / 418(61.7)$ \\
\hline mMRC (mean, SD) & $1.61(1.01)$ \\
\hline $\mathrm{mMRC} \geq 2(\mathrm{~N}, \%)$ & 403/834 (48.3) \\
\hline $\begin{array}{l}\text { Severe acute exacerbation within 1-year } \\
\text { before enrollment }(N, \%)\end{array}$ & $93(10.9)$ \\
\hline \multicolumn{2}{|l|}{ Pulmonary function test, mean(SD) } \\
\hline Initial FVC post (L)/(\%) & $3.18(0.82) / 87.6(18.6)$ \\
\hline Initial FEV1 post (L)/(\%) & $1.56(0.55) / 60.9(19.7)$ \\
\hline Initial FEV1 $\geq 50 \%(N, \%)$ & $586(68.6)$ \\
\hline Initial FEV1/FVC ratio post, mean(SD) & $49.2(11.7)$ \\
\hline \multicolumn{2}{|l|}{ BDR criteria, N (\%) } \\
\hline BDR >12\% and $200 \mathrm{ml}$ (FEV1) (GOLD) & $167(19.6)$ \\
\hline $\mathrm{BDR} \geq 12 \%$ and $200 \mathrm{ml}$ (FEV1 or FVC) (ATS) & $255(29.9)$ \\
\hline $\mathrm{BDR} \geq 15 \%$ (FEV1) (ACCP) & $187(21.9)$ \\
\hline $\mathrm{BDR}>8 \%(\mathrm{FEV} 1)$ & $383(44.9)$ \\
\hline $\begin{array}{l}\mathrm{BDR} \geq 15 \% \text { and } 400 \mathrm{ml} \text { (FEV1) } \\
\text { (Spanish ACOS) }\end{array}$ & $30(3.5)$ \\
\hline $\mathrm{BDR}>12 \%$ and $400 \mathrm{ml}$ (FEV1) (ACOS GINA) & $30(3.5)$ \\
\hline Post FEV1\% - pre FEV1 \% $\geq 10 \%$ (ERS) & $124(14.5)$ \\
\hline
\end{tabular}

SNUH Seoul National University Hospital Airway Registry, CODA COPD in Dusty Area Registry, KOCOSS Korean COPD Subgroup Study, KOLD Korean Obstructive Lung Disease Cohort, $N$ number, SD standard deviation, NR not recorded, CAT COPD assessment test, SGRQ St. George's respiratory questionnaire, $m M R C$ modified medical research council dyspnea scale, FEV1 forced expiratory volume in one second, FVC forced vital capacity, BDR bronchodilator reversibility experienced severe $\mathrm{AE}$ at least 1 year prior to cohort enrollment. The initial mean value of FEV1 was $1.56 \mathrm{~L}$ (SD 0.55).

Among the 854 patients, BDR positivity differed according to the criteria used for the response. The positive $\mathrm{BDR}$ rate ranged from 0.9 to $61.6 \%$ across the cohorts and according to BDR criteria. Among the criteria, the criterion of BDR $>8 \%$ FEV1 yielded a relatively high positive rate (33.6-61.6\%) in every cohort compared to the other positive BDR criteria. The major criteria for ACOS in the Spanish guidelines (15\% and $400 \mathrm{ml}$ in FEV1) showed the lowest rate of BDR positivity among the criteria.

During the 1-year follow-up period, the MPR of ICS/ LABA was 0.52 (SD 0.44), and the MPR of LAMA was 0.54 (SD 0.43). About $10 \%$ of patients experienced severe $\mathrm{AE}$ during the 1-year follow-up period, ranging from 5.5 to $12.0 \%$ in all cohorts. The highest rate of severe $\mathrm{AE}$ occurred in patients from the KOCOSS cohort. (Table 2)

Several factors including body mass index (BMI), comorbidity of diabetes mellitus (DM), symptom scores, and the experience of severe $\mathrm{AE}$ before cohort enrollment were revealed to be significant in our analysis. Among the BDR criteria, GOLD (BDR $>12 \%$ and $200 \mathrm{ml} \mathrm{FEV1)}$ and ATS (BDR $\geq 12 \%$ and $200 \mathrm{ml} \mathrm{FEV1}$ or FVC) showed a difference in positive rates between the severe $\mathrm{AE}(+)$ group and the severe $\mathrm{AE}(-)$ group (Additional file 1: Table S1). Adjusted ORs were calculated by adjusting for BMI, symptom score of mMRC ( $\geq 2$ vs. $<2$ ), comorbidity of DM, initial FEV1\% ( $\geq 50$ vs. $<50$ ), ICS/LABA MPR, and severe AE before cohort enrollment. Use of the GOLD and ATS criteria was associated with a decreased risk of severe $\mathrm{AE}(\mathrm{aOR}=0.37$, $95 \% \mathrm{CI}=0.15-0.91$ for GOLD; $\mathrm{aOR}=0.51 ; 95 \% \mathrm{CI}=0.28$ 0.96 for ATS). All seven BDR criteria increased the goodness of fit estimated by the AIC in each model, and the amounts of improvement were similar among the seven criteria. In the sensitivity analysis for patients with a smoking history $\geq 10$ PY, BDR positivity from the GOLD criteria still predicted a significantly decreased risk of severe $\mathrm{AE}$ in COPD patients $(\mathrm{aOR}=0.36,95 \% \mathrm{CI}=0.14-0.95)$ (Table 3$)$.

We compared the rate of severe AE between BDR positive and BDR negative patients during 1 year of follow up using different BDR criteria. Patients who showed BDR positivity experienced less severe $\mathrm{AE}$ than patients who showed BDR negativity when evaluated using the GOLD or ATS criteria ( $3.6 \%$ vs. $10.9 \%, p=0.004$ for GOLD, $5.9 \%$ vs. $11.0 \%, p=0.02$ for ATS) (Fig. 2).

When we calculated the risk of severe $\mathrm{AE}$ according to various BDR criteria stratified by ICS/LABA and LAMA MPR, there were significant interactions between ICS/ LABA MPR and the GOLD or ERS criteria (post FEV1\%-pre FEV1\% $210 \%)(p=0.044$ and $p=0.018$, respectively). If patients were treated with ICS/LABA for more than 6 months (MPR over 0.5), the rate of severe $\mathrm{AE}$ was reduced in cases of positive BDR according to 
Table 2 Treatment and outcomes of the participants

\begin{tabular}{llllll}
\hline Characteristics & $\begin{array}{l}\text { Total } \\
(n=854)\end{array}$ & $\begin{array}{l}\text { SNUH } \\
(n=101)\end{array}$ & $\begin{array}{l}\text { CODA } \\
(n=110)\end{array}$ & $\begin{array}{l}\text { KOCOSS } \\
(n=325)\end{array}$ & $\begin{array}{l}\text { KOLD } \\
(n=318)\end{array}$ \\
\hline Treatment & & & & & \\
ICS/LABA use: yes (\%) & $544 / 836(65.1)$ & $53 / 91(58.2)$ & 0.20 & $201 / 317(63.4)$ & $270(84.9)$ \\
ICS/LABA MPR, mean (SD) & $0.52(0.44)$ & $0.44(0.43)$ & $0.13(0.32)$ & $0.49(0.42)$ & $0.70(0.39)$ \\
LAMA use: yes (\%) & $564 / 830(68.0)$ & $61 / 91(67.0)$ & $39(35.5)$ & $250 / 311(80.4)$ & $214(67.3)$ \\
LAMA MPR, mean (SD) & $0.54(0.43)$ & $0.50(0.43)$ & $0.26(0.40)$ & $0.66(0.39)$ & $0.53(0.43)$ \\
Severe acute exacerbation (\%) & $81 / 854(9.4)$ & $6 / 101(5.9)$ & $6 / 110(5.5)$ & $39 / 325(12.0)$ & $30 / 318(9.4)$ \\
\hline
\end{tabular}

ICS/LABA inhaled corticosteroid/long-acting beta-agonist, LAMA long-acting muscarinic antagonist, MPR medication possession ratio, SD standard deviation

GOLD or ERS criteria (Fig. 3 and Additional file 1: Table S2). Among patients with $\geq 10$ PY, only BDR positivity according to the ERS criteria showed an effect modification through the use of ICS/LABA use $(p=0.021)$. There was no effect modification by LAMA occurred when modeling the effect of positive BDR on the risk of severe AE (Additional file 1: Table S2). In addition, no interaction was found between FEV1\% ( $\geq 50 \%$ vs. $<50 \%)$ or drug wash-out before enrollment (wash-out vs. no wash-out), and positive $\mathrm{BDR}$ on the risk of severe AE (data not shown). Even in the analysis $\mathrm{f}=$ of propensity score-matched participants, a positive BDR according to the GOLD criteria predicts severe $\mathrm{AE} . \quad(\mathrm{aOR}=0.27,95 \% \mathrm{CI}=0.10-0.75$, $p=0.012) \quad$ The balanced baseline characteristics between matched groups are presented in Additional file 1: Table S3.

\section{Discussion}

To our knowledge, this is the first study to investigate the differences in treatment outcomes according to BDR criteria using prospective COPD cohorts. Our study showed that a positive BDR according to the GOLD criteria predicts a decreased risk of severe $\mathrm{AE}$ in COPD patients. The GOLD criteria showed a statistically significant relationship with the development of severe $\mathrm{AE}$, and models using these criteria had the lowest AIC value. We did not find any significant association between BDR positivity and severe AE from other criteria (except ATS criteria in all participants). These results were consistent even in a sensitivity analysis which only included only patients with a smoking history of at least 10 PY.

The GOLD criteria require a $>12 \%$ and $200 \mathrm{ml}$ increase in FEV1 for a positive result. Although BDR criteria vary among various professional societies, and a

Table 3 Risk of severe acute exacerbation according to different BDR criteria

\begin{tabular}{|c|c|c|c|c|c|}
\hline & COR $(95 \% \mathrm{Cl})$ & $p$-value & $\mathrm{aOR}^{\mathrm{a}}(95 \% \mathrm{Cl})$ & $p$-value & AlC \\
\hline \multicolumn{6}{|l|}{ All participants $(n=854)$} \\
\hline BDR $>12 \%$ and $200 \mathrm{ml}$ (FEV1) (GOLD) & $0.30(0.13-0.71)$ & 0.01 & $0.37(0.15-0.91)$ & 0.03 & 471.470 \\
\hline $\mathrm{BDR} \geq 12 \%$ and $200 \mathrm{ml}$ (FEV1 or FVC) (ATS) & $0.51(0.28-0.90)$ & 0.02 & $0.51(0.28-0.96)$ & 0.04 & 472.485 \\
\hline $\mathrm{BDR} \geq 15 \%$ (FEV1) (ACCP) & $0.73(0.40-1.32)$ & 0.29 & $0.53(0.28-1.02)$ & 0.06 & 473.416 \\
\hline $\mathrm{BDR}>8 \%(\mathrm{FEV} 1)$ & $1.04(0.66-1.64)$ & 0.87 & $0.94(0.57-1.55)$ & 0.80 & 477.245 \\
\hline BDR $\geq 15 \%$ and $400 \mathrm{ml}$ (FEV1) (Spanish ACOS) & $0.32(0.04-2.39)$ & 0.27 & $0.51(0.06-4.07)$ & 0.53 & 476.726 \\
\hline BDR $>12 \%$ and $400 \mathrm{ml}$ (FEV1) (ACOS GINA) & $0.32(0.04-2.39)$ & 0.27 & $0.51(0.06-4.07)$ & 0.53 & 476.726 \\
\hline Post FEV1\% - pre FEV1 \% $\geq 10 \%$ (ERS) & $0.53(0.24-1.18)$ & 0.12 & $0.78(0.33-1.84)$ & 0.58 & 476.984 \\
\hline \multicolumn{6}{|c|}{ Participants with smoking history $\geq 10 P Y$ (a sensitivity analysis, $n=728$ ) } \\
\hline BDR $>12 \%$ and $200 \mathrm{ml}$ (FEV1) (GOLD) & $0.29(0.11-0.72)$ & 0.01 & $0.36(0.14-0.95)$ & 0.04 & 399.119 \\
\hline $\mathrm{BDR} \geq 12 \%$ and $200 \mathrm{ml}$ (FEV1 or FVC) (ATS) & $0.57(0.31-1.05)$ & 0.07 & $0.60(0.31-1.15)$ & 0.12 & 401.829 \\
\hline $\mathrm{BDR} \geq 15 \%$ (FEV1) (ACCP) & $0.70(0.37-1.35)$ & 0.29 & $0.56(0.28-1.12)$ & 0.10 & 401.406 \\
\hline $\mathrm{BDR}>8 \%(\mathrm{FEV} 1)$ & $1.02(0.61-1.69)$ & 0.95 & $0.94(0.54-1.64)$ & 0.84 & 404.324 \\
\hline $\mathrm{BDR} \geq 15 \%$ and $400 \mathrm{ml}$ (FEV1) (Spanish ACOS) & $0.35(0.05-2.60)$ & 0.30 & $0.61(0.08-4.85)$ & 0.64 & 404.022 \\
\hline $\mathrm{BDR}>12 \%$ and $400 \mathrm{ml}$ (FEV1) (ACOS GINA) & $0.35(0.05-2.60)$ & 0.30 & $0.61(0.08-4.85)$ & 0.64 & 404.022 \\
\hline Post FEV1\% - pre FEV1 $\% \geq 10 \%$ (ERS) & $0.53(0.22-1.26)$ & 0.15 & $0.89(0.35-2.24)$ & 0.80 & 404.301 \\
\hline
\end{tabular}

$B D R$ bronchodilator reversibility, $P Y$ pack-year, $c O R$ crude odds ratios, $a O R$ adjusted ORs, AIC Akaike Information Criterion

${ }^{a}$ Adjusted by BMl, symptom score of $\mathrm{mMRC} \geq 2$ vs $<2$, comorbidity of diabetes mellitus, initial FEV $1 \% \geq 50$ vs $<50$, medication possession ratio of inhaled corticosteroid/long-acting beta-agonist, and severe acute exacerbation within 1 year before enrollment 


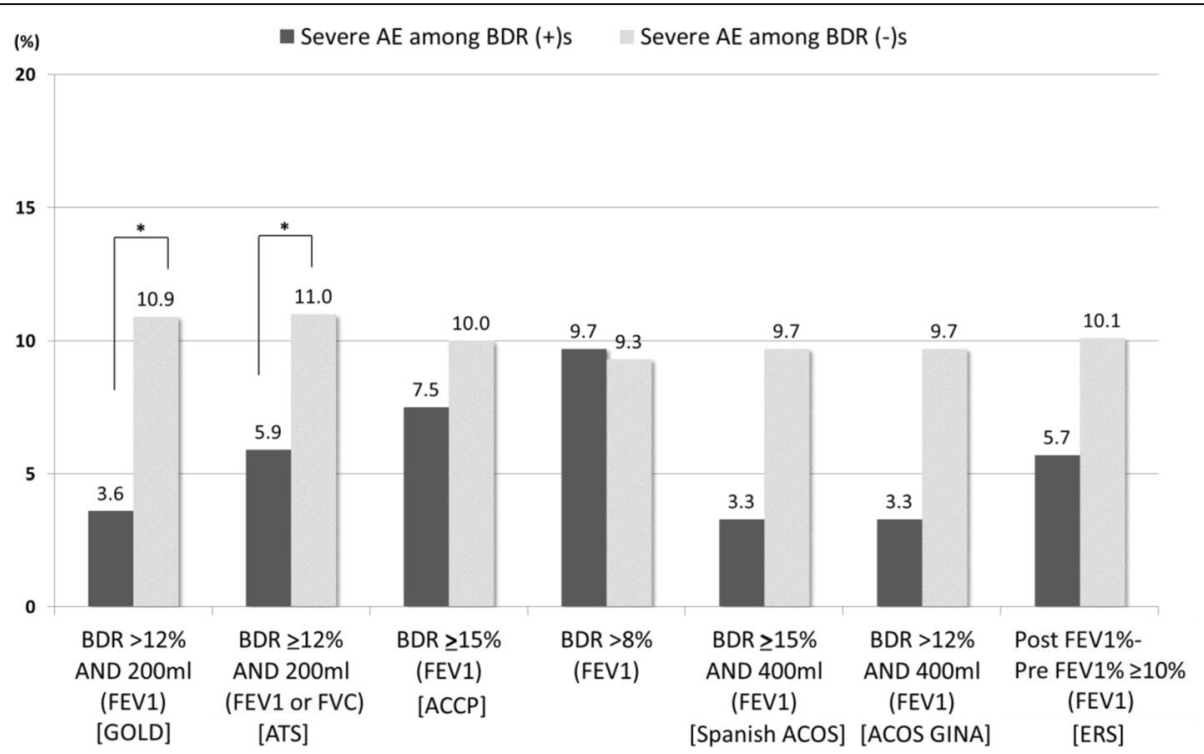

Fig. 2 Proportion of patients with severe acute exacerbation according to BDR positivity. * with a statistical significance of $p$-value $<0.05$ $B D R$ bronchodilator reversibility, AE acute exacerbation, FEV1 forced expiratory volume in one second, FVC forced vital capacity

standard definition has not been established [1, 13-17], reports suggest that a $12-15 \%$ increase in FEV1 compared to the baseline exceeds normal within-subject variability and response to placebo inhalation $[19,20]$. When baseline FEV1 is low, a high improvement in the percentage can be possible with only a small improvement in the absolute volume. Because of this, use of an absolute volume increase of $200 \mathrm{ml}$ has emerged as an alternative to using a percentage increase.

The usefulness of BDR positivity as a prognostic factor has been controversial $[8,11,21]$. BDR positivity favors a good treatment outcome in some studies, but demonstrates poor disease related outcomes in others. For example, Marin et al. reported a result similar to ours in that a positive BDR was significantly associated with a prolonged time to first hospitalization. However, theirs was a retrospective study [21]. Our results were somewhat different from PLATINO study, in which a positive BDR according to the ATS criteria and wheezing in the last 12 months showed a higher risk of hospitalization [11]. Self-reported wheezing might be a more severe symptom or a reflection of exacerbation, which could contribute to the worse outcome in these patients. This inconsistency might be due to the different study designs and ethnicity.

Our present study using prospective cohorts suggests that BDR positivity according to the GOLD criteria can predict a decreased risk of severe AE risk in univariate, multivariate, sensitivity and propensity score-matched analyses. Although the ATS criteria showed a similar result in all participants, statistical significance was not reached in a sensitivity analysis that excluded non- smokers and smokers with a history of less than 10 PY. Other criteria did not show a significant ability to predict severe AE. However, all aORs for positive BDR and severe $\mathrm{AE}$ were below 1.0 (range of $\mathrm{aOR}=0.37-0.94$ ). The mechanism of how BDR positivity in COPD patients leads to a decreased risk of severe AE has not been fully established, and there are several possible explanations for this. First, it could be the case that many asthma patients were misdiagnosed as positive BDR COPD patients. However, the sensitivity analysis excluded patients with a smoking history of less than 10 PY showed similar results, which suggests that asthma contamination alone is not an adequate explanation. Second, a positive BDR per se could predict a future positive response to drugs. Interestingly, in our study there was a significant interaction between ICS/LABA treatment and the effect of $\mathrm{BDR}$ on severe $\mathrm{AE}$. A positive BDR according to the GOLD criteria predicted a decrease in the risk of severe $\mathrm{AE}$ only in patients who had an ICS/LABA MPR $>0.5$ (aOR for ICS/ LABA MPR $>0.5=0.18 ; 95 \% \mathrm{CI}=0.04-0.78$; aOR for ICS $/$ LABA MPR $\leq 0.5=0.95,95 \%$ CI $=0.29-3.10$; $\mathrm{p}$ for interaction $=0.044$ ), although statistical significance was not reached in a sensitivity analysis that included only subjects with $\geq 10 \mathrm{PY}$. Our results suggest that a positive BDR could predict a response to ICS/LABA treatment. In support of this, it has been reported that increased reversibility of short-acting beta-2 agonists is associated with an increase in eosinophils and in exhaled nitric oxide (NO) [22]. This reversibility could be a phenotype of a good responder to inhaled corticosteroids [23-27]. We found there to be no effect modification by LAMA treatment for 


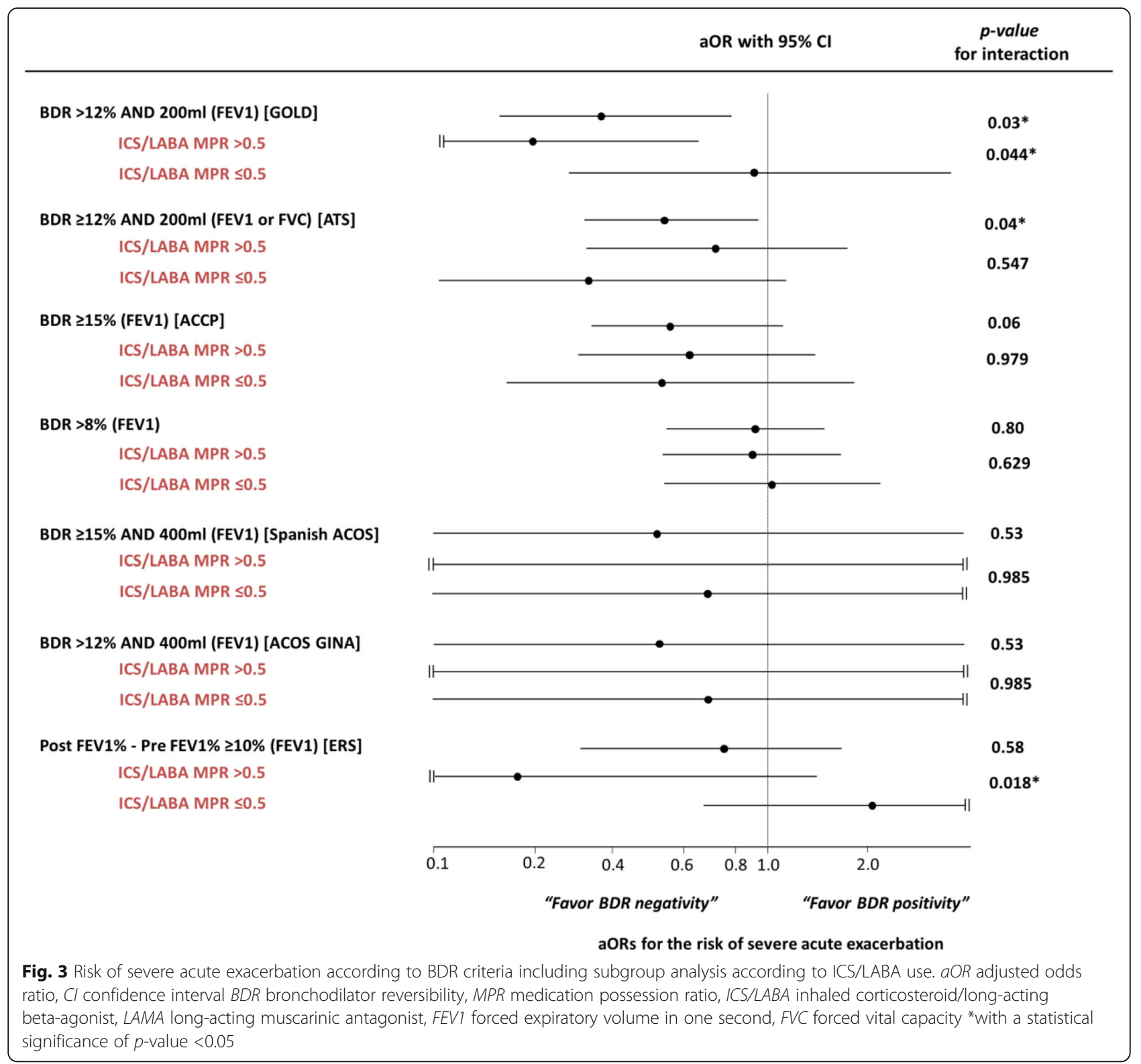

the effect of $\mathrm{BDR}$ on the incidence of severe $\mathrm{AE}$ in our study (all $\mathrm{p}$ for interactions $>0.05$ ).

This study has several key strengths. First, it is the first prospective study to compare clinical outcomes in COPD patients using various BDR positivity criteria. Second, this study was performed in a non-Western region and therefore represents the characteristics of COPD patients from non-Western countries. The results of this study could be helpful in future clinical trials or longitudinal studies. Third, a relatively large number of COPD patients from four different COPD cohorts were included in this analysis. The results of this study could therefore provide clinically significant information in a real-world setting. Last, we applied propensity scorematched analysis to strengthen the results.
This study also has several limitations. First, we did not investigate long-term outcomes, including mortality, owing to the limitations of the follow-up periods in these cohorts. Second, we did not have access to a large number of patients who had experienced severe AE. However, the number of patients with severe $\mathrm{AE}$ was sufficient to establish a multiple logistic regression model. Third, as a pooled analysis of four different cohorts, bias might have been present that rendered our sample unrepresentative of the total South Korean population. When we examined the patient demographic data of the four cohorts in this study, however, we found that they seemed to have similar baseline FEV1 and symptom scores. This allowed us to use a combined sample to represent COPD patients in South Korea. Fourth, small 
number of severe $\mathrm{AE}$ events in participants might have led to a lack of statistical power. Fifth, the main finding of this study might be comprise random statistical results due to an increase in type 1 errors from the multiple analyses; this was inevitable when determining if each of the BDR criteria was related to the risk of exacerbation. Sixth, 15 patients experienced multiple severe $\mathrm{AE}$ events during follow-up, which were not considered in the logistic models. Last, we only included participants who were followed-up for at least 1 year because the international guidance recommends that a study duration should be at least 1 year if the objective of the study is to investigate exacerbations [28]; this might form a selection bias by excluding many participants who were followed up for less than 1 year.

\section{Conclusions}

The key pathophysiology of COPD is a persistent and progressive airflow limitation, that is reversible, to some extent, following the administration of a short-acting bronchodilator. Our results found that a positive BDR in the GOLD and ATS criteria could predict a decreased risk of severe $\mathrm{AE}$ in COPD patients. Even in the analysis for smokers, positivity in the GOLD criteria was still able to reflect the risk of severe $\mathrm{AE}$ of COPD. Longer ICS/LABA use provides a positive effect modification on this relationship. Other criteria for BDR positivity did not work for predicting the severe $\mathrm{AE}$ risk of $\mathrm{COPD}$ patients.

\section{Additional file}

Additional file 1: Supplement data. (DOCX $44 \mathrm{~kb}$ )

\section{Abbreviations}

AE: Acute exacerbation; AIC: Akaike information criterion; BDR: Bronchodilator reversibility; CAT: COPD assessment test; COPD: Chronic obstructive lung disease; FEV1: Forced expiratory volume in one second; FVC: Forced vital capacity; ICS: Inhaled corticosteroid; LABA: Long-acting beta agonists; LAMA: Long-acting muscarinic antagonist; mMRC: modified medical research council dyspnea scale; MPR: Medication possession ratio; SGRQ: St. George's respiratory questionnaire

\section{Acknowledgements}

None.

\section{Funding}

This study is not supported by any other source.

\section{Availability of data and materials}

The datasets used for the current study are available from the corresponding author on reasonable request.

\section{Authors' contributions}

$\mathrm{CL}$ planned this study, had access to the data and took responsibility for the integrity of the data and data analysis. JK and CL contributed to study concept and design, analysis, and preparation of the manuscript. WJK, SHL, MGL, KS, KHY, $J \mathrm{~L}, \mathrm{SYL}, \mathrm{JON}, \mathrm{HH}, \mathrm{YH}, \mathrm{MNL}, \mathrm{CY}, \mathrm{KSJ}$, and SL contributed to data collection and preparation of manuscript. All authors read and approved the final manuscript.

\section{Competing interests}

The authors declare that they have no competing interests.

\section{Consent for publication}

Not required due to study design.

\section{Ethics approval and consent to participate}

Participants from four different prospective COPD cohort studies in Korea were enrolled: Seoul National University Hospital (SNUH) Airway Registry (NCT02527486), COPD in Dusty Area (CODA) Registry (KCT0000552), Korean COPD Subgroup Study (KOCOSS) (NCT02800499), and Korean Obstructive Lung Disease Cohort (KOLD). The study design and methods were approved by the Institutional Review Board of Seoul National University Hospital (IRB No. H-1507-030-686) and informed consent was obtained from each patient of all cohort studies.

\section{Publisher's Note}

Springer Nature remains neutral with regard to jurisdictional claims in published maps and institutional affiliations.

\section{Author details}

${ }^{1}$ Division of Pulmonary and Critical Care Medicine, Department of Internal Medicine, National Medical Center, Seoul, Republic of Korea. ${ }^{2}$ Department of Internal Medicine and Environmental Health Center, Kangwon National University Hospital, Chuncheon, Republic of Korea. ${ }^{3}$ Division of Pulmonary and Critical Care Medicine, Department of Internal Medicine, Seoul National University Hospital, 101 Daehak-Ro, Jongno-Gu, Seoul 03080, Republic of Korea. ${ }^{4}$ Department of Internal Medicine, The Catholic University of Korea, St. Paul's Hospital, Seoul, Republic of Korea. ${ }^{5}$ Division of Pulmonary, Allergy \& Critical Care Medicine, Hallym University Chuncheon Sacred Heart Hospital, Chuncheon, Republic of Korea. ${ }^{6}$ Division of Pulmonology and Allergy, Regional Center for Respiratory Disease, Yeungnam University Medical Center, Daegu, Republic of Korea. ${ }^{7}$ Division of Pulmonary and Critical Care Medicine, Department of Internal Medicine, Konkuk University Medical Center, Konkuk University School of Medicine, Seoul, Korea. ${ }^{8}$ Division of Respiratory and Critical Care Medicine, Department of Internal Medicine, CHA Bundang Medical Center, CHA University, Seongnam, Republic of Korea. ${ }^{9}$ Division of Pulmonary and Critical Care Medicine, Department of Medicine, Kangbuk Samsung Hospital, Sungkyunkwan University School of Medicine, Seoul, Republic of Korea. ${ }^{10}$ Department of Pulmonary Medicine,

Soonchunhyang University Cheonan Hospital, Cheonan-si, Republic of Korea.

${ }^{11}$ Department of Medicine, Soonchunhyang University Gumi's Hospital, Gumi, North Kyungsang Province, Republic of Korea. ${ }^{12}$ Division of Pulmonary Medicine, Department of Internal Medicine, Hallym University Sacred Heart Hospital, Hallym University Medical School, Anyang, Republic of Korea.

${ }^{13}$ Division of Pulmonary and Critical Care Medicine, Department of Internal Medicine, Asan Medical Center, University of Ulsan College of Medicine, Seoul, Republic of Korea.

Received: 7 January 2017 Accepted: 16 May 2017 Published online: 30 May 2017

References

1. Global Initiative for Chronic Obstructive Lung Disease(GOLD). Global strategy for the diagnosis, management, and prevention of chronic obstructive pulmonary disease. Updated 2016. Available from: http://www. goldcopd.org/. 2016

2. Chapman KR, Mannino DM, Soriano JB, Vermeire PA, Buist AS, Thun MJ, Connell C, Jemal A, Lee TA, Miravitlles M, Aldington S, Beasley R. Epidemiology and costs of chronic obstructive pulmonary disease. Eur Respir J. 2006:27(1):188-207.

3. Lopez AD, Shibuya K, Rao C, Mathers CD, Hansell AL, Held LS, Schmid V, Buist S. Chronic obstructive pulmonary disease: current burden and future projections. Eur Respir J. 2006;27(2):397-412.

4. Vestbo J, Hurd SS, Agusti AG, Jones PW, Vogelmeier C, Anzueto A, Barnes PJ, Fabbri LM, Martinez FJ, Nishimura M, Stockley RA, Sin DD, RodriguezRoisin R. Global strategy for the diagnosis, management, and prevention of chronic obstructive pulmonary disease: GOLD executive summary. Am J Respir Crit Care Med. 2013;187(4):347-65. 
5. Reid DW, Soltani A, Johns DP, Bish R, Williams TJ, Burns GP, Walters EH. Bronchodilator reversibility in Australian adults with chronic obstructive pulmonary disease. Intern Med J. 2003;33:572-7.

6. Calverley PM, Burge PS, Spencer S, Anderson JA, Jones PW. Bronchodilator reversibility testing in chronic obstructive pulmonary disease. Thorax. 2003:58:659-64

7. Calverley PM, Albert P, Walker PP. Bronchodilator reversibility in chronic obstructive pulmonary disease: use and limitations. Lancet Respir Med. 2013;1(7):564-73.

8. Hanania NA, Celli BR, Donohue JF, Martin UJ. Bronchodilator reversibility in COPD. Chest. 2011;140(4):1055-63.

9. Mahler DA, Donohue JF, Barbee RA, Goldman MD, Gross NJ, Wisniewski ME, Yancey SW, Zakes BA, Rickard KA, Anderson WH. Efficacy of Salmeterol Xinafoate in the treatment of COPD. Chest. 1999;115:957-65.

10. Hardin M, Silverman EK, Barr RG, Hansel NN, Schroeder JD, Make BJ, Crapo $J D$, Hersh CP, Investigators CO. The clinical features of the overlap between COPD and asthma. Respir Res. 2011;12:127.

11. Menezes AM, Montes de Oca M, Perez-Padilla R, Nadeau G, Wehrmeister FC, Lopez-Varela MV, Muino A, Jardim JR, Valdivia G, Talamo C, Team P. Increased risk of exacerbation and hospitalization in subjects with an overlap phenotype: COPD-asthma. Chest. 2014;145(2):297-304.

12. Ward H, Cooper BG, Miller MR. Improved criterion for assessing lung function reversibility. Chest. 2015;148(4):877-86.

13. American Thoracic Society. Lung function testing: selection of reference values and interpretative strategies. Am Rev Respir Dis. 1991;144(5):1202-18.

14. Report of the Committee on Emphysema American College of Chest Physicians. Criteria for the assessment of reversibility in airways obstruction. Chest. 1974;65(5):552-3.

15. Soler-Catalũna JJ, Cosío B, Izquierdo JL, López-Campos JL, Marín JM, Agüero R, Baloira A, Carrizo S, Esteban C, Galdiz JB, González MC, Miravitlles M, Monsó E, Montemayor T, Morera J, Ortega F, Peces-Barba G, Puente L, Rodríguez JM, Sala E, Sauleda J, Soriano JB, Viejor JL. Consensus Document on the Overlap Phenotype COPD-Asthma in COPD. Arch Bronconeumol. 2012;48(9):331-7.

16. Diagnosis of Diseases of Chronic Airflow Limitation:Asthma, COPD and Asthma-COPD Overlap Syndrome(ACOS). Updated 2015. Available from: http://www.goldcopd.org/. 2015.

17. Siafakas NM, Vermeire $P$, Pride NB, Paoletti P, Gibson J, Howard P, Yernault JC, Decramer M, Higenbottam T, Postma DS, Rees J. Optimal assessment and management of chronic obstructive pulmonary disease (COPD). Eur Respir J. 1995;8(8):1398-420.

18. Miller MR, Hankinson J, Brusasco V, Burgos F, Casaburi R, Coates A, Crapo R, Enright $P$, van der Grinten $C P$, Gustafsson $P$, Jensen $R$, Johnson DC, MacIntyre N, McKay R, Navajas D, Pedersen OF, Pellegrino R, Viegi G, Wanger J, Force AET. Standardisation of spirometry. Eur Respir J. 2005;26(2): 319-38.

19. Pennock BE, Rogers RM, McCaffree R. Changes in measured spirometric indices. Chest. 1981;80:91-9.

20. Sourk RL, Nugent KM. Bronchodilator testing: confidence intervals derived from placebo inhalations. Am Rev Respir Dis. 1983;128:153-7.

21. Marin JM, Ciudad M, Moya V, Carrizo S, Bello S, Piras B, Celli BR, Miravitlles M. Airflow reversibility and long-term outcomes in patients with COPD without comorbidities. Respir Med. 2014;108(8):1180-8.

22. Papi A, Romagnoli M, Baraldo S, Braccioni F, Guzzinati I, Saetta M, Ciaccia A, Fabbri LM. Partial Reversibility of airflow limitation and increased exhaled $\mathrm{NO}$ and sputum eosinophilia in chronic obstructive pulmonary disease. Am J Respir Crit Care Med. 2000;162:1773-7.

23. Weiner $P$, Weiner $M$, Azgad $Y$, Zamir D. Inhaled Budesonide therapy for patients with stable COPD. Chest. 1995;108:1568-71.

24. Siva R, Green RH, Brightling CE, Shelley M, Hargadon B, McKenna S, Monteiro W, Berry M, Parker D, Wardlaw AJ, Pavord ID. Eosinophilic airway inflammation and exacerbations of COPD: a randomised controlled trial. Eur Respir J. 2007;29(5):906-13.

25. Lee J-H, Lee YK, Kim E-K, Kim T-H, Huh JW, Kim WJ, Lee JH, Lee S-M, Lee S, Lim SY, Shin TR, Yoon HI, Sheen SS, Kim N, Seo JB, Oh Y-M, Lee SD. Responses to inhaled long-acting beta-agonist and corticosteroid according to COPD subtype. Respir Med. 2010;104(4):542-9.

26. Miravitlles M. Arguments in favor of inhaled corticosteroids in COPD by phenotype instead of by severity. Arch Bronconeumol. 2011;47(6):271-3.

27. DiSantostefano RL, Li H, Rubin DB, Stempel DA. Which patients with chronic obstructive pulmonary disease benefit from the addition of an inhaled corticosteroid to their bronchodilator? A cluster analysis. BMJ Open 2013;3(4):e001838-e.

28. Martinez FJ, Donohue JF, Rennard SI. The future of chronic obstructive pulmonary disease treatment-difficulties of and barriers to drug development. Lancet. 2011;378(9795):1027-37.

\section{Submit your next manuscript to BioMed Central and we will help you at every step:}

- We accept pre-submission inquiries

- Our selector tool helps you to find the most relevant journal

- We provide round the clock customer support

- Convenient online submission

- Thorough peer review

- Inclusion in PubMed and all major indexing services

- Maximum visibility for your research

Submit your manuscript at www biomedcentral.com/submit
C Biomed Central 